\title{
ResearchArticle
}

\section{Evaluation of oil formulations of Nomuraea rileyi (Farlow) Samson against Spodoptera litura under laboratory conditions}

\author{
T. SHARMILA, K. MANJULA AND T. MURALI KRISHNA
}

\begin{abstract}
SUMMARY
Three oil formulations of entomopathogenic fungus Nomuraea rileyi were evaluated for their efficacy along with crude formulation against third instar Spodoptera litura during 2011-2012 at the Department of Entomology, S.V. Agricultural College, Tirupati. Mean larval mortalities of 96.67, 93.33, 86.67 and 76.67 per cent, respectively were recorded with groundnut, sunflower, coconut oil based formulations and crude formulation of $N$. rileyi at highest concentration i.e., $1 \times 10^{8}$ spores $\mathrm{ml}^{-1}$ at 10 DAT. More than 70 per cent larval mortalities of $S$. litura were obtained with the concentrations above $1 \times 10^{6}$ spores per $\mathrm{ml}$ in case of groundnut oil and sunflower oil based formulations. The mortalities gradually reduced with concentration showing the least at $1 \times 10^{2}$ spores $^{-1}$. Incubation period, was in negative correlation with the concentration of $N$. rileyi in all the formulations. Pupal mortalities and malformed adults emergence showed positive association with concentration of $N$. rileyi against $S$. litura larvae.
\end{abstract}

Key Words : N. rileyi, Oil formulation, Lab evaluation, S. litura

How to cite this article : Sharmila, T., Manjula, K. and Krishna, T. Murali (2015). Evaluation of oil formulations of Nomuraea rileyi (Farlow) Samson against Spodoptera litura under laboratory conditions. Internat. J. Plant Sci., 10 (1): 29-32.

Article chronicle : Received : 29.05.2014; Revised : 11.11.2014; Accepted : 26.11.2014 